ist, ein Antimonstäbchen, welches dick genug sein muss, um nicht völlig von der Flüssigkeit bedeckt zu werden. Am besten legt man das Stäbchen so nahe dem Rande des Gefässes, dass zwischen diesem und dem Metall etwas Flüssigkeit eingeschlossen ist. Das Metallstäbchen wird mit dem negativen Pole der Batterie verbunden. In die gewissermaassen abgesperrte Flüssigkeit taucht man einen dicken Platindraht, der mit dem positiven Pole verbunden ist, nahe dem Antimonmetalle ein, so dass ein ziemlich lạnges Drahtstück nahe neben diesem liegt. Während der lebhaftesten Gasentwickelung sieht man vom Antimon sich schwarze Flocken abscheiden, wahrscheinlich Wasserstoff-Antimon; und wirkt die Batterie kräftig genug, so beginnen alsbald fortwährende kleine Detonationen, die um so stärker sind, je grösser die zerplatzenden Blasen werden. Diese verbrennen mit lebhaftem Glanze und einer weissen Flamme, wie sie das Antimonwasserstoffgas zeigt. Ein weisser Dampf, der sich dabei ausscheidet, macht es sehr wahrscheinlich, dass die Erscheinung in der That durch selbstentzündliches Antimonwasserstoffgas hervorgebracht wird. Halle, d. 9. März 184.5.

\title{
XLI.
}

\section{Vorläufige Notiz über die Identität des Leukols und Chinolins.}

Dr. A ug. Wilh. Hof man $n$ hat seine Untersuchungen über das Steinkohlentheeröl fortgesetzt. Durch eine sorgfältige Vergleichung der Eigenschaften des Leukols und Chinolins sind die

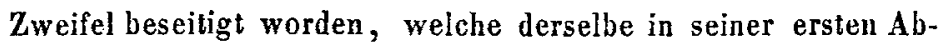
handlung über die Identität dieser beiden Körper ausgesprochen hat. Leukolund Chinolin sind identisch. Das vollkommen gereinigte Leukol giebt mit Chromsäure den gelben krystallinischen Niederschlag, welchen Gerhard $t$ als charakteristisch für das Chinolin bezeichnet, ebenfalls.

Diese Thatsache, welche demnächst im Detail mitgetheilt werden soll, wurde bereits im verflossenen Sommer in dem hiesigen Laboratorium ermittelt und während meiner Abwesenheit, unter Andern, Prof. Wöhler mitgetheilt. 